\title{
Predictors of placebo response in peripheral neuropathic pain: insights from pregabalin clinical trials
}

\author{
This article was published in the following Dove Press journal: \\ Journal of Pain Research \\ I June 2015 \\ Number of times this article has been viewed
}

Roy Freeman'

Birol Emir ${ }^{2}$

Bruce Parsons ${ }^{2}$

'Autonomic and Peripheral Nerve Laboratory, Department of

Neurology, Beth Israel Deaconess

Medical Center, Boston, MA, USA;

${ }^{2}$ Pfizer Inc, New York, NY, USA
Correspondence: Roy Freeman Autonomic and Peripheral Nerve Laboratory, Department of Neurology, Beth Israel Deaconess Medical Center, I Deaconess Road, Boston, MA 02215 USA $\mathrm{Tel}+\mathrm{I} 6176328454$

Fax + I 6176320852

Email rfreeman@bidmc.harvard.edu
Background: Greater understanding of factors associated with the high placebo-response rates noted in recent neuropathic pain trials may improve trial design. This study investigated placebo response and its predictors in pregabalin trials in patients with diabetic peripheral neuropathy (DPN) or postherpetic neuralgia.

Patients and methods: Individual patient data from 16 randomized, placebo-controlled, double-blind trials of pregabalin in 3,053 patients with DPN and 1,460 patients with postherpetic neuralgia were pooled (by condition and all together) in order to investigate the placebo response and its predictors. Univariate and multivariate analyses were performed across all 16 trials to identify predictors of change in pain score in patients. Trials with a $>2$-point mean reduction in pain score at endpoint with placebo were designated high placebo response and were compared with low placebo-response trials (those with a $\leq 2$-point mean reduction) with respect to patient and study characteristics.

Results: Three high placebo-response studies were identified, with all in DPN patients and all conducted postapproval of pregabalin. Younger age, higher mean baseline pain score, longer study duration, higher ratio of patients on active treatment to placebo, and study conducted postapproval were all significantly associated with a higher placebo response $(P<0.05)$. There was a trend towards an increased placebo response in all studies over time without any corresponding change in the response to pregabalin.

Conclusion: Consideration of the factors identified here as contributing to a higher placebo response could help improve the sensitivity and accuracy of clinical trials in patients with neuropathic pain.

Keywords: diabetic peripheral neuropathy, postherpetic neuralgia

\section{Introduction}

A number of recent randomized, double-blind clinical trials in neuropathic pain have failed to demonstrate a significant difference between active treatment and placebo, despite previous positive results. ${ }^{1-4}$ At the same time, many recent studies in this patient population have had high placebo-response rates. ${ }^{5,6}$ The placebo effect is known to be particularly high for analgesics, ${ }^{7}$ and it has been widely suggested that the higher placebo response may have contributed to the difficulty in discerning a positive treatment effect in recent trials. ${ }^{1,8}$

The pregabalin neuropathic pain database offers a unique opportunity to study the placebo response across clinical trials with the same drug and a similar trial design. This is the first analysis specifically investigating the placebo response and its predictors in clinical trials of pregabalin in patients with diabetic peripheral neuropathy 
(DPN) or postherpetic neuralgia (PHN). In this report, we present the results of univariate and multivariate analyses and comparisons between pregabalin studies in DPN and PHN in which there was a high placebo response with studies in which there was a low placebo response, in an attempt to identify aspects of study design and patient characteristics that may contribute to the placebo response.

Identifying factors associated with a higher placebo response could help investigators design clinical trials that result in lower placebo-response rates, potentially increasing the sensitivity and accuracy of efficacy measures in these trials. $^{9}$

\section{Material and methods}

\section{Study design and patient population}

For this analysis, patient-level data were pooled from 16 randomized, placebo-controlled, parallel-group, doubleblind trials of pregabalin for the treatment of DPN or PHN, all sponsored by Pfizer Inc. and approved by relevant institutional review boards (Table 1). Of these, nine trials were in patients with DPN, five were in PHN, and two were in mixed populations of DPN and PHN patients. DPN and PHN data were analyzed individually and combined. Studies were conducted in centers in Asia, Australia, Canada, Europe, Latin America, the Middle East, South Africa, and the United States. The study lengths ranged from 5 to 14 weeks, and doses of pregabalin ranged from 75 to $600 \mathrm{mg}$ /day. In those studies with flexible dosing, pregabalin was escalated in doses of $150,300,450$, and $600 \mathrm{mg} /$ day and titrated in weekly intervals based on patient's individual response and tolerability. Trials included are identified by study number: $1008-014,{ }^{10}$ 1008-029, ${ }^{11} 1008-030,{ }^{12} 1008-040,{ }^{12} 1008-045,{ }^{13} 1008-155,{ }^{14}$ $1008-127,{ }^{15} 1008-131,{ }^{16} 1008-149,{ }^{17} 1008-196,{ }^{18} \mathrm{~A} 0081004$ (ClinicalTrials.gov identifier: NCT00159666), ${ }^{19}$ A0081030 (NCT00156078), A0081060 (NCT00159679), ${ }^{20}$ A0081071 (NCT00143156), A0081081 (NCT00301223), ${ }^{21}$ and A0081163 (NCT00553475). ${ }^{22}$ Primary data from studies 1008-040 (conducted in 49 centers in ten countries across Europe, Australia, and South Africa), A0081030 (conducted in 47 centers in 19 countries across Asia, Europe, Latin America, and the Middle East), and A0081071 (conducted in 50 centers in the United States) are reported here for the first time.

Key entry criteria included the following: at least 18 years of age; primary diagnosis of either DPN (type 1 or 2 diabetes with painful, distal, symmetrical, or sensorimotor polyneuropathy) or $\mathrm{PHN}$ (pain present for $\geq 3$ months after healing of the herpes zoster skin rash); and mean baseline pain score at least 4, as measured on an 11-point numeric rating scale (NRS; where $0=$ no pain and $10=$ worst possible pain), for 4 or more days during the week prior to randomization or pain score of at least $40 \mathrm{~mm}$ on the $100 \mathrm{~mm}$ visual analog scale of the Short-Form McGill Pain Questionnaire ${ }^{23}$ at screening and randomization.

Patients were excluded if they suffered from any neurological disorders or had severe pain unrelated to DPN or PHN that could confound assessment of pain. Patients with DPN were required to discontinue all analgesic medications. Medications that could affect painful symptoms of DPN were prohibited, with the exception of acetaminophen ( $\leq 3-4 \mathrm{~g}$ /day), aspirin ( $\leq 325 \mathrm{mg}$ /day for myocardial infarction or transient ischemic attack prophylaxis), and serotonin reuptake inhibitors (no dose changes 30 days prior to or during the study). Patients with PHN were permitted to continue treatment if they were on a stable regimen of analgesics, anti-inflammatories, or antidepressants. The primary endpoint in all studies was change in endpoint mean pain score, defined as the last seven daily pain score entries (scored on an 11-point NRS) for pregabalin versus placebo.

\section{Statistical analysis}

Data for the last observation carried forward mean reduction in pain score at endpoint in each trial were analyzed for each group. Trials in which there was a $>2$-point mean reduction in pain score in the placebo arm at endpoint were designated "high placebo response," whereas those with a mean reduction of $\leq 2$ points in the placebo arm were designated "low placebo response." A 2-point mean change was selected because this degree of improvement is generally considered to be clinically meaningful in patients with chronic pain. ${ }^{24}$ High placebo-response and low placebo-response trials were pooled and compared with respect to patient and study characteristics. Separately, trials in which there was a $>1.5$ point mean change in pain score were compared with those with a $\leq 1.5$-point change. As the placebo response in PHN trials was typically lower than in DPN trials, with no PHN trials having a 2-point mean change, the 1.5-point mean change analysis was conducted in order to compare those PHN trials with a higher response to those with a lower response. A univariate analysis of patient-level data was performed to identify predictors of change in pain score in the placebo group. Categorical variables were analyzed using a chi-square-based method and continuous variables were analyzed using analysis of variance. The relationship between pain scores and secondary efficacy endpoints, Patient Global Impression of Change (PGIC), and sleep 


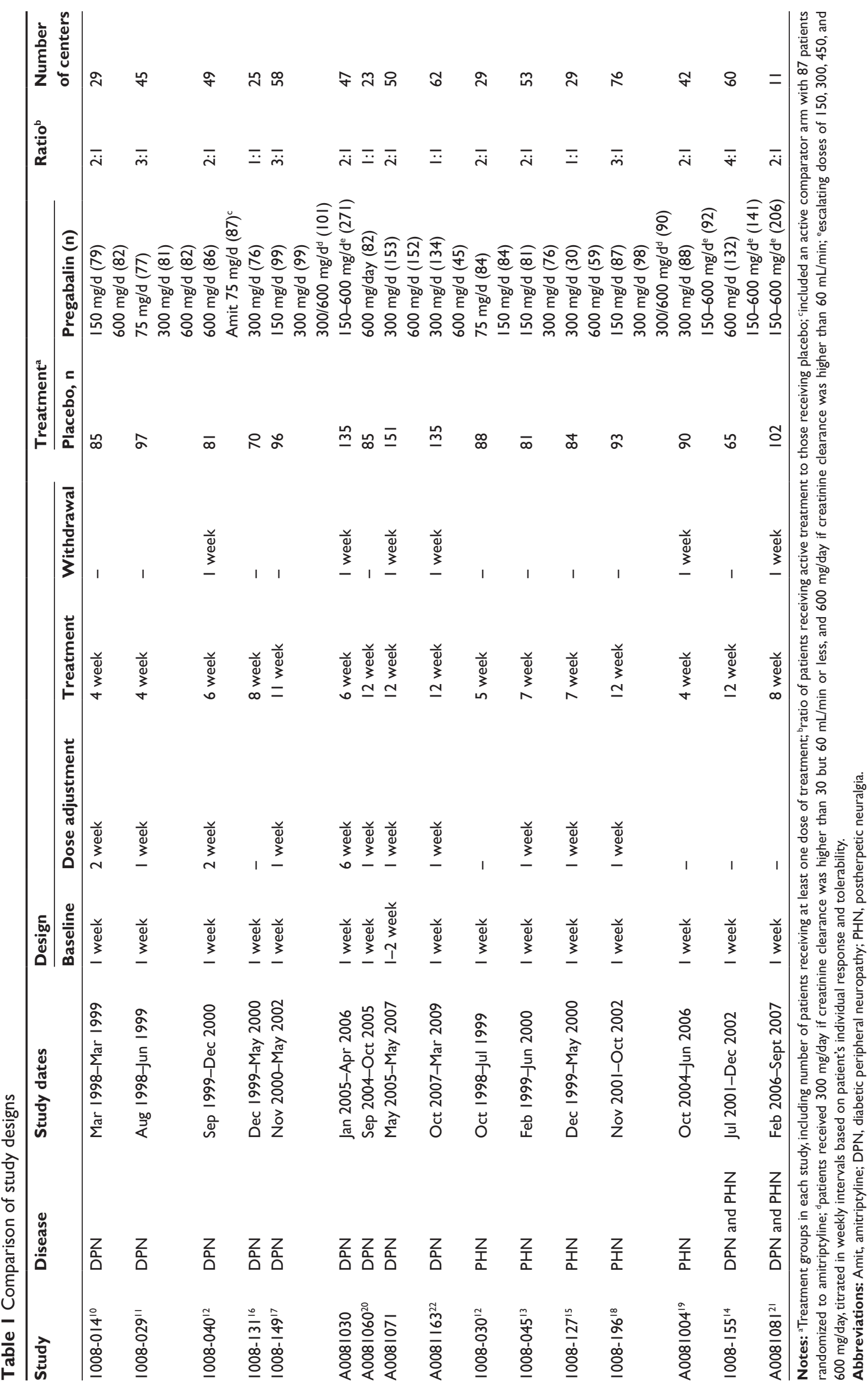


interference (by 11-point NRS) in the placebo group were also assessed using an initial test of independence (which strongly rejected the hypothesis that being a placebo pain responder was independent of being a PGIC or sleep responder) followed by calculating the probability that a placebo pain responder would also be a PGIC responder and that a placebo pain responder would also be a sleep responder. A multivariate classification and regression-tree analysis of factors potentially contributing to the placebo response in individual patients was also conducted.

\section{Results}

\section{Primary efficacy outcomes}

This analysis included 16 studies in which a total of 4,513 patients received $\geq 1$ dose of treatment (2,999 pregabalin and 1,514 placebo). This included 3,053 patients with DPN (2,015 pregabalin and 1,038 placebo) and 1,460 with PHN (984 pregabalin and 476 placebo). Results for the primary efficacy outcome (mean pain score at final assessment compared with baseline) for each study are shown in Table 2. The two studies conducted in patients with DPN or PHN (1008-155 and A0081081) were each split and examined as DPN patients only and PHN patients only (resulting in 18 total studies included).

Full details of these studies are available in the literature, ${ }^{10,11,13-22}$ with the exception of studies A0081030, A0081071, and, in part, 1008-040, which are reported here for the first time. In study A0081030, there was no significant difference in mean pain score at endpoint with flexible-dose pregabalin (150-600 mg/day) compared with placebo. In study A0081071, there was also no significant difference in mean pain score at endpoint with pregabalin (300 or $600 \mathrm{mg} /$ day) compared with placebo. In study $1008-$ 040, while there was no significant difference in mean pain score at endpoint with pregabalin $600 \mathrm{mg} /$ day, amitriptyline $75 \mathrm{mg} /$ day significantly improved pain score (least squares mean difference from placebo, $-0.93 ; 95 \%$ confidence interval, -1.65 to $-0.22 ; P=0.0110)$. In each of these studies, safety and tolerability were comparable to previously reported pregabalin studies.

\section{High and low placebo-response studies}

Studies A0081030, A0081071, and A0081081 (DPN patients only) were designated as high placebo-response studies $(>2$-point mean change in pain score with placebo) (Figure 1A and B; Table 2). All high placebo-response studies were in patients with DPN and all were negative studies, failing to show a significant treatment difference between pregabalin and placebo. In total, six of the 18 studies included in this analysis were negative studies (Figure 1A and B; Table 2). Of the three negative studies designated as low placebo response in this analysis, two were close to the cutoff of $\mathrm{a}>2$-point mean change in pain score (studies 1008-040, change in pain score of -1.93; and 1008-155 [PHN patients], change in pain score of -1.86). The other negative study (1008-030) had a low placebo response (change in pain score of -0.97 ) but the pregabalin doses in the actively treated group were low (75 and $150 \mathrm{mg}$ /day).

Study design and baseline demographic and clinical characteristics of patients receiving placebo in high placeboresponse and low placebo-response studies are shown in Table 3. High placebo-response compared with low placeboresponse studies tended to be of longer duration, to have been conducted postapproval of pregabalin, to have higher ratios of active treatment to control (Figure 1A-D), and to include flexible dosing (Table 1).

No PHN studies were designated high placebo-response studies; however, there were three PHN studies with a $>1.5$-point mean reduction in pain score in the placebo arm (1008-155 [PHN patients], A0081004, and A0081081 [PHN patients]). Compared with PHN studies with a lower placebo response, these studies also tended to include patients with a younger mean age ( 65.8 versus 71.5 years) and shorter mean duration of PHN (24.9 versus 37.4 months). In addition, two of these three studies were conducted postapproval of pregabalin, and all three had an active treatment to placebo ratio $\geq 2: 1$ and included a flexible-dosing arm (Figure 1B; Table 1).

The impact of patient age and sex on the change in mean pain score for high and low placebo-response studies is shown in Table 4.

\section{Predictors of placebo response}

An analysis of univariate predictors of change in pain in pooled placebo arms (across high and low placebo-response studies) is shown in Table 5 for categorical variables and Table 6 for continuous variables. Studies conducted postapproval of pregabalin for the treatment of DPN or PHN had a significantly higher placebo response than those conducted preapproval ( $P<0.0001$ for DPN/PHN studies combined). There was a higher placebo response in females than in males in both DPN and PHN studies $(P<0.0001$ for DPN/ PHN studies combined). DPN studies with a higher ratio of active treatment to control $(\geq 2: 1)$ had a higher placebo response than those with lower ratios $(P<0.0001)$. This difference was not apparent in PHN studies alone but was in DPN/PHN studies combined $(-1.60$ versus -1.22 ; $P<0.0001)$. 
Table 2 Primary efficacy outcomes

\begin{tabular}{|c|c|c|c|c|c|c|}
\hline \multirow[t]{2}{*}{ Study } & \multirow[t]{2}{*}{ Treatment } & \multirow[t]{2}{*}{$\mathbf{n}^{\mathrm{a}}$} & \multirow{2}{*}{$\begin{array}{l}\text { Endpoint mean } \\
\text { pain score, LS } \\
\text { mean }\end{array}$} & \multirow{2}{*}{$\begin{array}{l}\text { Change in pain } \\
\text { score from baseline, } \\
\text { LS mean (SE) }\end{array}$} & \multicolumn{2}{|c|}{$\begin{array}{l}\text { Treatment difference } \\
\text { (pregabalin versus placebo) }\end{array}$} \\
\hline & & & & & $\begin{array}{l}\text { LS mean difference } \\
(95 \% \mathrm{Cl})\end{array}$ & $P$-value \\
\hline \multicolumn{7}{|l|}{ DPN } \\
\hline \multirow[t]{3}{*}{$1008-014^{10}$} & Placebo & 82 & 5.55 & $-1.16(0.23)$ & - & - \\
\hline & 150 mg/d & 79 & 5.11 & $-1.60(0.24)$ & $-0.44(-1.08$ to 0.20$)$ & 0.1763 \\
\hline & $600 \mathrm{mg} / \mathrm{d}$ & 82 & 4.29 & $-2.42(0.23)$ & $-1.26(-1.89$ to -0.64$)$ & $<0.0001$ \\
\hline \multirow[t]{4}{*}{$1008-02911$} & Placebo & 97 & 5.06 & $-1.35(0.21)$ & - & - \\
\hline & 75 mg/d & 77 & 4.91 & $-1.50(0.24)$ & $-0.15(-0.76$ to 0.46$)$ & 0.6267 \\
\hline & $300 \mathrm{mg} / \mathrm{d}$ & 81 & 3.80 & $-2.61(0.23)$ & $-1.26(-1.86$ to -0.65$)$ & $<0.0001$ \\
\hline & $600 \mathrm{mg} / \mathrm{d}$ & 81 & 3.60 & $-2.81(0.23)$ & $-1.45(-2.06$ to -0.85$)$ & $<0.0001$ \\
\hline \multirow[t]{3}{*}{$1008-040^{12, b, c}$} & Placebo & 80 & 4.60 & $-1.93(0.27)$ & - & - \\
\hline & $600 \mathrm{mg} / \mathrm{d}$ & 86 & 3.96 & $-2.57(0.26)$ & $-0.64(-1.37$ to 0.08$)$ & 0.0822 \\
\hline & Amit 75 mg/d & 87 & 3.67 & $-2.86(0.25)$ & $-0.93(-1.65$ to -0.22$)$ & 0.0110 \\
\hline \multirow[t]{2}{*}{$|008-13|^{16}$} & Placebo & 69 & 5.46 & $-0.88(0.28)$ & - & - \\
\hline & $300 \mathrm{mg} / \mathrm{d}$ & 75 & 3.99 & $-2.35(0.26)$ & $-1.47(-2.19$ to -0.75$)$ & $<0.0001$ \\
\hline \multirow[t]{4}{*}{$1008-149^{17}$} & Placebo & 93 & 4.66 & $-1.77(0.26)$ & - & - \\
\hline & $150 \mathrm{mg} / \mathrm{d}$ & 96 & 4.33 & $-2.10(0.26)$ & $-0.33(-0.94$ to 0.28$)$ & 0.2849 \\
\hline & $300 \mathrm{mg} / \mathrm{d}$ & 96 & 4.48 & $-1.95(0.26)$ & $-0.17(-0.79$ to 0.43$)$ & 0.5580 \\
\hline & $300 / 600 \mathrm{mg} / \mathrm{d}^{d}$ & 98 & 3.69 & $-2.74(0.25)$ & $-0.97(-1.58$ to -0.36$)$ & 0.0018 \\
\hline $1008-155$ & Placebo & 46 & 4.86 & $-1.78(0.37)$ & - & - \\
\hline \multirow[t]{2}{*}{$\left(\mathrm{DPN}\right.$ patients) ${ }^{14}$} & $600 \mathrm{mg} / \mathrm{d}$ & 94 & 3.55 & $-3.09(0.27)$ & $-1.31(-2.16$ to -0.46$)$ & 0.0028 \\
\hline & $150-600 \mathrm{mg} / \mathrm{d}$ & 103 & 3.73 & $-2.91(0.26)$ & $-1.13(-1.97$ to -0.29$)$ & 0.0088 \\
\hline \multirow[t]{2}{*}{ A008I030,e } & Placebo & 134 & 3.85 & $-2.54(0.19)^{\mathrm{e}}$ & - & - \\
\hline & $150-600 \mathrm{mg} / \mathrm{d}$ & 267 & 3.54 & $-2.85(0.14)$ & $-0.30(-0.74$ to 0.13$)$ & 0.1700 \\
\hline \multirow[t]{2}{*}{$A 0081060^{20}$} & Placebo & 83 & 4.82 & $-1.62(0.25)$ & - & - \\
\hline & $600 \mathrm{mg} / \mathrm{d}$ & 80 & 3.54 & $-2.90(0.26)$ & $-1.28(-1.96$ to -0.60$)$ & 0.0003 \\
\hline \multirow[t]{3}{*}{ A008I07/c,e } & Placebo & 149 & 4.16 & $-2.32(0.20)^{\mathrm{e}}$ & - & - \\
\hline & $300 \mathrm{mg} / \mathrm{d}$ & $15 \mid$ & 3.97 & $-2.51(0.20)$ & $-0.19(-0.71$ to 0.33$)$ & 0.4744 \\
\hline & $600 \mathrm{mg} / \mathrm{d}$ & 148 & 3.84 & $-2.64(0.20)$ & $-0.32(-0.85$ to 0.20$)$ & 0.4530 \\
\hline A008I08I & Placebo & 70 & 3.89 & $-2.32(0.25)^{\mathrm{e}}$ & - & - \\
\hline (DPN patients) $)^{21, c, e}$ & $150-600 \mathrm{mg} / \mathrm{d}$ & 143 & 3.50 & $-2.7 \mid(0.20)$ & $-0.39(-0.92$ to 0.14$)$ & 0.1523 \\
\hline \multirow[t]{3}{*}{$A 0081163^{22}$} & Placebo & 135 & 4.83 & $-1.20(0.21)$ & - & - \\
\hline & $300 \mathrm{mg} / \mathrm{d}$ & 134 & 4.20 & $-1.82(0.21)$ & $-0.63(-1.09$ to -0.17$)$ & 0.0075 \\
\hline & $600 \mathrm{mg} / \mathrm{d}$ & 45 & 4.08 & $-1.94(0.32)$ & $-0.74(-1.39$ to -0.09$)$ & 0.0254 \\
\hline \multicolumn{7}{|c|}{ 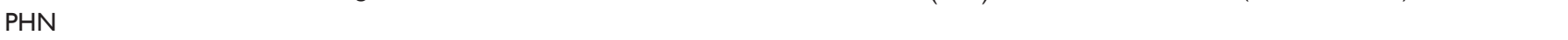 } \\
\hline $1008-030^{12, c}$ & Placebo & 87 & 5.59 & $-0.97(0.21)$ & - & - \\
\hline & 75 mg/d & 83 & 5.46 & $-1.11(0.21)$ & $-0.14(-0.71$ to 0.43$)$ & 0.6361 \\
\hline & $150 \mathrm{mg} / \mathrm{d}$ & 82 & 5.52 & $-1.05(0.22)$ & $-0.07(-0.64$ to 0.50$)$ & 0.7999 \\
\hline $1008-045^{13}$ & Placebo & 81 & 6.33 & $-0.52(0.22)$ & - & - \\
\hline & $150 \mathrm{mg} / \mathrm{d}$ & 81 & 5.14 & $-1.71(0.22)$ & $-1.20(-1.81$ to -0.58$)$ & 0.0002 \\
\hline & $300 \mathrm{mg} / \mathrm{d}$ & 76 & 4.76 & $-2.09(0.23)$ & $-1.57(-2.20$ to -0.95$)$ & $<0.0001$ \\
\hline $1008-127^{15}$ & Placebo & 84 & 5.29 & $-1.06(0.24)$ & - & - \\
\hline & $300 / 600 \mathrm{mg} / \mathrm{d}^{d}$ & 88 & 3.60 & $-2.75(0.24)$ & $-1.69(-2.33$ to -1.05$)$ & 0.0001 \\
\hline $1008-196^{18}$ & Placebo & 93 & 6.14 & $-0.53(0.23)$ & - & - \\
\hline & $150 \mathrm{mg} / \mathrm{d}$ & 87 & 5.26 & $-1.41(0.24)$ & $-0.88(-1.53$ to -0.23$)$ & 0.0077 \\
\hline & $300 \mathrm{mg} / \mathrm{d}$ & 98 & 5.07 & $-1.60(0.23)$ & $-1.07(-1.70$ to -0.45$)$ & 0.0008 \\
\hline & $300 / 600 \mathrm{mg} / \mathrm{d}^{d}$ & 88 & 4.35 & $-2.32(0.24)$ & $-1.79(-2.43$ to -1.15$)$ & 0.0001 \\
\hline $1008-155$ & Placebo & 16 & 5.08 & $-1.86(0.71)$ & - & - \\
\hline (PHN patients) $)^{14, c}$ & $600 \mathrm{mg} / \mathrm{d}$ & 34 & 3.64 & $-3.31(0.53)$ & $-1.45(-2.95$ to 0.06$)$ & 0.0601 \\
\hline & $150-600 \mathrm{mg} / \mathrm{d}$ & 36 & 3.89 & $-3.06(0.49)$ & $-1.20(-2.69$ to 0.30$)$ & 0.1147 \\
\hline$A 0081004^{19}$ & Placebo & 83 & 4.86 & $-1.60(0.21)$ & - & - \\
\hline & $300 \mathrm{mg} / \mathrm{d}$ & 81 & 3.86 & $-2.60(0.21)$ & $-1.00(-1.55$ to -0.45$)$ & 0.0004 \\
\hline & $150-600 \mathrm{mg} / \mathrm{d}$ & 90 & 3.50 & $-2.96(0.20)$ & $-1.36(-1.90$ to -0.83$)$ & $<0.000$ I \\
\hline A008I08I & Placebo & 32 & 4.94 & $-1.65(0.42)$ & - & - \\
\hline$(\mathrm{PHN} \text { patients })^{21}$ & $150-600 \mathrm{mg} / \mathrm{d}$ & 60 & 3.67 & $-2.93(0.36)$ & $-1.28(-2.15$ to -0.41$)$ & 0.0045 \\
\hline
\end{tabular}

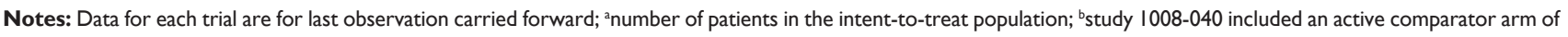
amitriptyline at $75 \mathrm{mg} /$ day; ' negative studies were those in which there was no significant difference at endpoint between pregabalin and placebo; ${ }^{\mathrm{d}}$ patients received $300 \mathrm{mg} /$ day

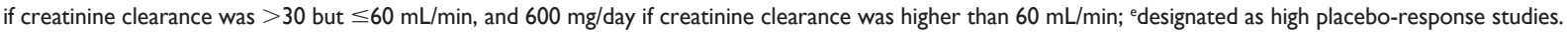

Abbreviations: Amit, amitriptyline; Cl, confidence interval; DPN, diabetic peripheral neuropathy; LS, least squares; PHN, postherpetic neuralgia; SE, standard error. 


\section{A DPN}

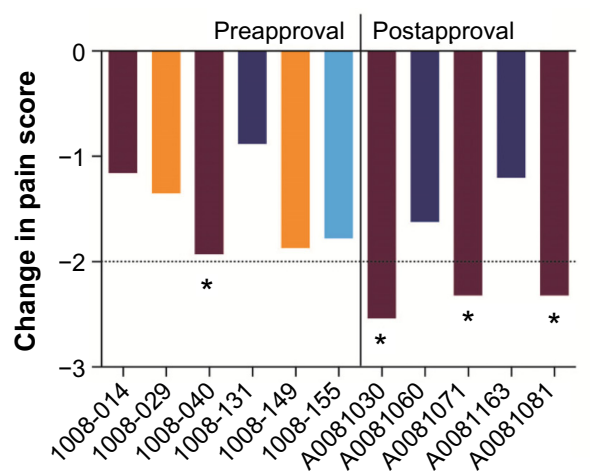

\section{B PHN}

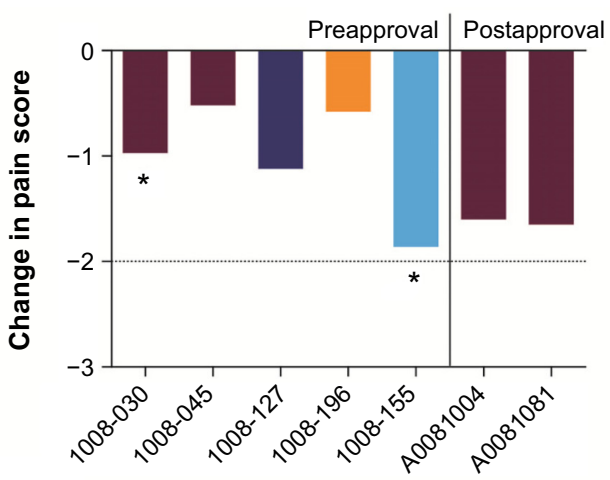

Ratio active: placebo

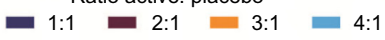
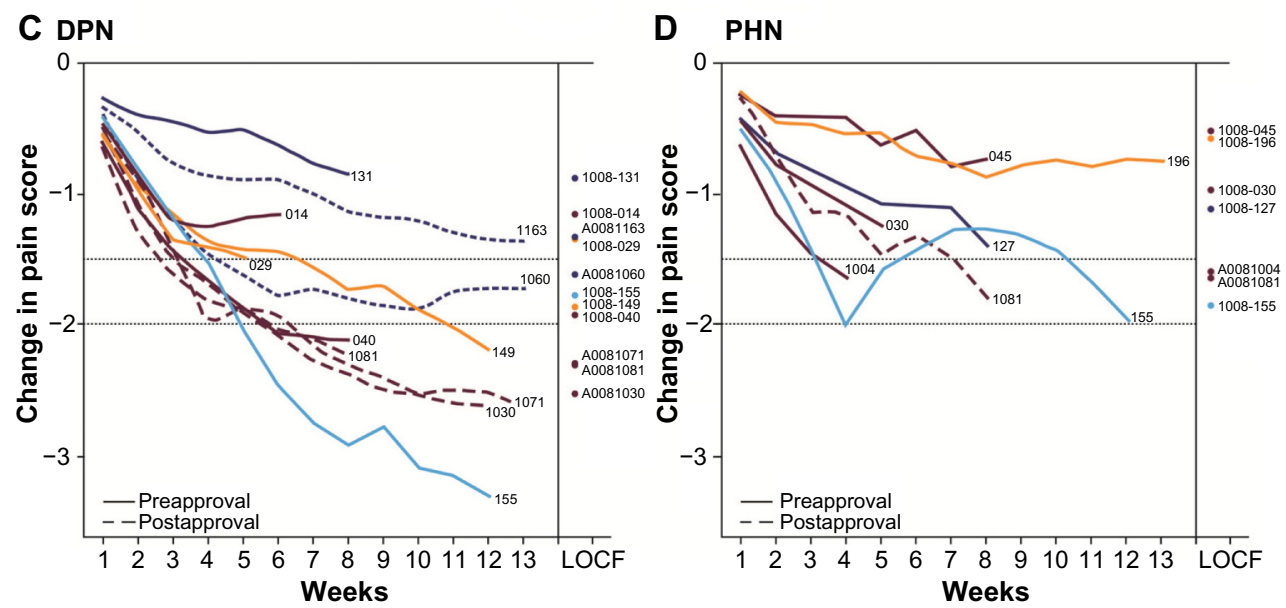

Figure I Mean change in placebo response at endpoint, by study week and by study completion date.

Notes: Ratio of active treatment to placebo in each trial (total number of patients on active treatment to placebo) for (A) diabetic peripheral neuropathy (DPN) and (B) postherpetic neuralgia (PHN) studies; The solid vertical line separates those studies that commenced preapproval of pregabalin (to the left of the line) and postapproval of pregabalin (to the right of the line); The dashed horizontal line shows the 2-point mean change in pain score at endpoint; Studies with a >2-point change (A008I030, A008I07I, A008I08I [DPN patients]) were designated high placebo-response studies; *Indicates trials that were negative (those in which there was no significant difference at endpoint between pregabalin and placebo); The least squares mean change in placebo response by study week for (C) DPN and (D) PHN studies; Study characteristics are shown by color of the line (ratio of active treatment to placebo) and solid or dashed lines (studies conducted pre- and postapproval, respectively); The position of the circles shown with study numbers indicates the last observation carried forward (LOCF) mean change for that study.

In both PHN and DPN studies, neither site recruitment numbers nor time of enrollment was associated with a higher placebo response. A higher number of sites per study was associated with a higher placebo response in DPN studies only.

Among the continuous variables assessed (Table 6), lower age, shorter duration of PHN, higher baseline pain score, and longer study duration were all significantly associated with a higher placebo response in the combined DPN/PHN population ( $P \leq 0.0002$ for each).

Change in pain score with placebo was also associated with a change in other patient-reported outcomes. For a patient receiving placebo classified as a pain responder ( $\geq 30 \%$ improvement in pain score at endpoint), there was an $82 \%$ probability that they would be a sleep responder
( $\geq 30 \%$ improvement in sleep interference score at endpoint) and a $64 \%$ probability that they would be a PGIC responder (symptoms either "very much improved" or "much improved"). Together, there was a $91 \%$ probability that a pain responder receiving placebo would be either a sleep responder or a PGIC responder.

Figure $1 \mathrm{C}$ and $\mathrm{D}$ shows the least squares mean change in pain score for placebo groups in each study by week, stratified by ratio of active treatment to placebo, and whether the study was conducted pre- or postapproval.

There has also been a trend toward an increased placebo response over time in these trials (Figure 2A and B). In contrast, over the same time period, the response to pregabalin (at doses of $300 \mathrm{mg} / \mathrm{day}, 600 \mathrm{mg} /$ day, and flexible dosing) has not meaningfully changed. Although the placebo response 
Table 3 Patient and study characteristics for the placebo population in high placebo-response and low placebo-response studies

\begin{tabular}{|c|c|c|c|}
\hline \multirow[t]{2}{*}{ Patient characteristics } & \multicolumn{2}{|l|}{ DPN } & \multirow{2}{*}{$\begin{array}{l}\text { PHN } \\
\text { Low } \\
\text { placebo } \\
\text { response } \\
(n=476)\end{array}$} \\
\hline & $\begin{array}{l}\text { High } \\
\text { placebo } \\
\text { response } \\
(n=353)\end{array}$ & $\begin{array}{l}\text { Low } \\
\text { placebo } \\
\text { response }^{\text {b }} \\
n=685)\end{array}$ & \\
\hline Age, mean (SD), y & $58.4(10.1)$ & $59.3(10.9)$ & $69.9(10.4)$ \\
\hline Female, n (\%) & $190(53.8)$ & $276(40.3)$ & $231(48.5)$ \\
\hline Male, n (\%) & $163(46.2)$ & $409(59.7)$ & $245(51.5)$ \\
\hline $\begin{array}{l}\text { Baseline pain score, } \\
\text { mean (SD) }\end{array}$ & $6.3(1.5)$ & $6.4(1.5)$ & $6.6(1.5)$ \\
\hline $\begin{array}{l}\text { Duration of } \mathrm{NeP} \text {, } \\
\text { mean }(\mathrm{SD}), \mathrm{y}\end{array}$ & $3.8(3.5)$ & $4.2(3.2)$ & - \\
\hline $\begin{array}{l}\text { Duration of DPN, } \\
\text { mean (SD), y }\end{array}$ & $4.3(4.0)$ & $4.9(3.7)$ & - \\
\hline $\begin{array}{l}\text { Duration of PHN, } \\
\text { mean (SD), mo }\end{array}$ & - & - & $33.8(36.9)$ \\
\hline \multicolumn{4}{|l|}{ Study characteristics } \\
\hline $\begin{array}{l}\text { Study duration, } \\
\text { mean (SD), wk }\end{array}$ & II.5 (3.7) & $9.1(3.8)$ & $7.0(3.3)$ \\
\hline \multicolumn{4}{|l|}{ Total site recruitment } \\
\hline $\begin{array}{l}\text { Patients per site, } \\
\text { mean (SD) }\end{array}$ & $5.8(4.2)$ & $3.8(2.2)$ & $3.7(2.2)$ \\
\hline$\leq 5, \mathrm{n}(\%)$ & $217(61.5)$ & $518(75.6)$ & $367(77.1)$ \\
\hline $6-8, \mathrm{n}(\%)$ & $74(21.0)$ & 157 (22.9) & $91(19.1)$ \\
\hline $9-11, n(\%)$ & $30(8.5)$ & $10(1.5)$ & $18(3.8)$ \\
\hline$\geq 12, n(\%)$ & $32(9.1)$ & 0 & 0 \\
\hline Discontinuations, n (\%) & $63(100)$ & $115(100)$ & $100(100)$ \\
\hline Adverse event & I8 (28.6) & $34(29.6)$ & $28(28.0)$ \\
\hline Lack of compliance & 0 & $7(6.1)$ & $2(2.0)$ \\
\hline Lack of efficacy & $14(22.2)$ & $5 I(44.3)$ & $45(45.0)$ \\
\hline Other & 31 (49.2) & $23(20.0)$ & $25(25.0)$ \\
\hline \multicolumn{4}{|c|}{ Pregabalin approval status, ${ }^{d} \mathrm{n}(\%)$} \\
\hline Preapproval & 0 & $467(68.2)$ & $36 \mid(75.8)$ \\
\hline Postapproval & $353(100)$ & $218(31.8)$ & $115(24.2)$ \\
\hline \multicolumn{4}{|c|}{ Ratio of active to control,e $\mathrm{n}(\%)$} \\
\hline $1: 1$ & 0 & $287(41.9)$ & $84(17.6)$ \\
\hline$\geq 2: 1$ & $353(100)$ & $398(58.1)$ & $392(82.4)$ \\
\hline
\end{tabular}

Notes: There were no high placebo-response studies in patients with PHN; No all studies recorded duration of illness; apooled placebo patients from studies A008I030, A008I07I, and A008I08I (DPN); ${ }^{b}$ pooled placebo patients from studies I008-0|4, 1008-029, 1008-040, I008-I3I, 1008-I49, 1008-I55 (DPN), A008I060 and A008I I63; ' pooled placebo patients from studies I008-030, 1008-045, 1008-127, 1008-I55 (PHN), I008-196, A008I004, and A008I08I (PHN); ${ }^{d}$ pregabalin approval

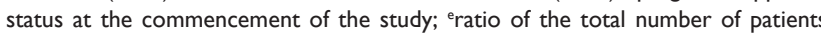
receiving active treatment to patients receiving placebo.

Abbreviations: DPN, diabetic peripheral neuropathy; mo, months; NeP, diabetic neuropathic pain; PHN, postherpetic neuralgia; SD, standard deviation; wk, week; y, years.

in studies in patients with PHN was typically less than that in patients with DPN, both sets of patients have shown a similar increase in mean placebo response in clinical trials over time.

A multivariate analysis of factors contributing to placebo response is shown in Figure 3. The highest placebo response was in patients who did not discontinue from the study due to lack of efficacy, were in a study conducted postapproval, in patients with DPN, with $\geq 36$ sites, and who remained in the study for $\geq 83.97 \%$ of its duration.

\section{Discussion}

To elucidate the factors involved in the placebo response, we analyzed the results of 16 trials of pregabalin in which 1,514 patients received placebo (1,038 with DPN and 476 with PHN). The major findings of the study are as follows: high placebo-response compared with low placebo-response studies tended to 1) be conducted postapproval of pregabalin; 2) have higher ratios of active treatment to control; 3) be of longer duration; 4) increase over time; and 5) be associated with changes in other patient-reported outcomes. There was no relationship to site recruitment numbers or time of enrollment in the study, and, contrary to previous reports, ${ }^{25}$ the placebo response was higher in flexible-dose studies.

The present data strongly support the importance of expectancy on the placebo effect. Awareness that a drug is an approved therapy is likely to enhance patient expectations and all high placebo-response studies in DPN occurred postapproval, whereas two of the three highest placebo-response studies in PHN occurred postapproval. Knowledge of the likelihood of receiving active drug versus placebo also may influence patients' expectations. In the trials in this analysis, patients were typically aware of their probability of receiving active treatment versus placebo. Pooled analyses in depression, ${ }^{26}$ migraine, ${ }^{27}$ and irritable bowel syndrome ${ }^{28}$ all support an inverse relationship between probability of receiving placebo and placebo response.

The present data, with drug to placebo ratios varying from 1:1 to 4:1, lend some support to these earlier studies. In univariate analyses of DPN and PHN, a higher treatment allocation ratio was significantly associated with a higher placebo response. In DPN, the lowest pre- and postapproval placebo responses occurred in studies with a 1:1 allocation, whereas the highest preapproval placebo response in PHN occurred in a trial with a 4:1 ratio. The regression-tree analysis demonstrated that approval status, but not treatment allocation ratio, was a predictor of placebo response. It is possible that expectations regarding treatment efficacy carry greater salience for research patients than expectations of treatment allocation, but this analysis is limited by the availability of only two postapproval PHN studies.

The major determinants of the effect of expectancy on outcome include susceptibility to suggestion, prior experience, learning, cultural perspectives on medical care, 
Table 4 Difference in mean change in pain score between pregabalin and placebo groups in high placebo-response and low placeboresponse studies stratified by age and sex

\begin{tabular}{|c|c|c|c|c|c|c|c|c|c|c|}
\hline \multicolumn{5}{|c|}{ High placebo response $^{a}$} & \multirow[t]{3}{*}{ Difference } & \multicolumn{4}{|c|}{ Low placebo response ${ }^{b}$} & \multirow[t]{3}{*}{ Difference } \\
\hline & \multicolumn{2}{|c|}{$\begin{array}{l}\text { Pregabalin } \\
(\mathrm{n}=709)\end{array}$} & \multicolumn{2}{|c|}{$\begin{array}{l}\text { Placebo } \\
(n=353)\end{array}$} & & \multicolumn{2}{|c|}{$\begin{array}{l}\begin{array}{l}\text { Pregabalin } \\
(n=2,290)\end{array} \\
\end{array}$} & \multicolumn{2}{|c|}{$\begin{array}{l}\text { Placebo } \\
(n=1,161)\end{array}$} & \\
\hline & $\mathbf{n}$ & Mean (SD)c & n & Mean (SD)c & & n & Mean (SD) ${ }^{c}$ & n & Mean (SD) ${ }^{c}$ & \\
\hline \multicolumn{11}{|l|}{ DPN } \\
\hline \multicolumn{11}{|l|}{ Age, y } \\
\hline $18-52$ & 195 & $-2.59(2.23)$ & 98 & $-2.36(2.31)$ & -0.23 & 319 & $-2.35(2.21)$ & 172 & $-1.80(2.02)$ & -0.56 \\
\hline $53-59$ & 194 & $-2.74(2.23)$ & 92 & $-2.02(2.06)$ & $-0.7 \mathrm{I}$ & 292 & $-2.54(2.42)$ & 138 & $-1.39(1.99)$ & -1.15 \\
\hline $60-66$ & 163 & $-2.98(2.32)$ & 94 & $-2.49(2.00)$ & -0.49 & 347 & $-2.35(2.20)$ & 191 & $-1.28(2.05)$ & -1.08 \\
\hline $67-89$ & 157 & $-2.21(2.25)$ & 69 & $-2.30(2.5 \mathrm{I})$ & 0.10 & 348 & $-2.37(2.48)$ & 184 & $-1.33(2.20)$ & -1.04 \\
\hline \multicolumn{11}{|l|}{ Sex } \\
\hline Female & 372 & $-2.76(2.33)$ & 190 & $-2.31(2.07)$ & -0.45 & 516 & $-2.55(2.37)$ & 276 & $-1.54(2.27)$ & -1.02 \\
\hline Male & 337 & $-2.50(2.19)$ & 163 & $-2.28(2.37)$ & -0.22 & 790 & $-2.30(2.29)$ & 409 & $-1.38(1.94)$ & -0.92 \\
\hline \multicolumn{11}{|l|}{$\mathbf{P H N}^{\mathrm{d}}$} \\
\hline \multicolumn{11}{|l|}{ Age, y } \\
\hline $18-52$ & - & - & - & - & - & 57 & $-1.66(2.24)$ & 33 & $-2.19(2.29)$ & 0.53 \\
\hline $53-59$ & - & - & - & - & - & 85 & $-1.76(2.36)$ & 38 & $-1.25(1.54)$ & $-0.5 \mathrm{I}$ \\
\hline $60-66$ & - & - & - & - & - & 158 & $-2.56(2.14)$ & 79 & $-1.18(2.06)$ & -1.38 \\
\hline $67-89$ & - & - & - & - & - & 679 & $-2.05(2.18)$ & 324 & $-0.83(1.77)$ & -1.22 \\
\hline$>89$ & - & - & - & - & - & 5 & $-2.08(4.35)$ & 2 & $0.14(0.20)$ & -2.22 \\
\hline \multicolumn{11}{|l|}{ Sex } \\
\hline Female & - & - & - & - & - & 506 & $-2.35(2.32)$ & 231 & $-1.12(1.92)$ & -1.23 \\
\hline Male & - & - & - & - & - & 478 & $-1.81(2.07)$ & 245 & $-0.91(1.82)$ & -0.89 \\
\hline
\end{tabular}

Notes: aPooled placebo patients from DPN studies A0081030, A008I07I, and A008I08I (DPN); ' pooled placebo patients from DPN studies 1008-014, 1008-029, I008-040, 1008-131, 1008-149, 1008-155 (DPN), A0081060, and A0081 I63; 'mean change (SD) from baseline in pain score at endpoint; 'pooled placebo patients from PHN studies 1008-030, 1008-045, 1008-127, 1008-155 (PHN), 1008-196, A0081004, and A008108I (PHN).

Abbreviations: DPN, diabetic peripheral neuropathy; PHN, postherpetic neuralgia; SD, standard deviation; $y$, years.

investigator-patient relationship, and other psychosocial factors. ${ }^{29,30}$ The present data suggest that to increase assay sensitivity and reduce likelihood of false-negative trials, more attention should be devoted to minimizing expectations in clinical trials. Increased awareness of the role played by verbal suggestions and conscious and unconscious signals conveyed during the course of the trial is necessary. Advocacy for the drug should be avoided, and, particularly in the postapproval environment, recruitment strategies and subject-investigator interactions should have an objective, dispassionate quality.

Consistent with other studies, ${ }^{1,31,32}$ our data show that the placebo response is greater in DPN than PHN studies. Earlier reports suggest that anatomical differences may underlie this observation. ${ }^{1}$ These authors theorized that PHN pathology is more likely to involve central sites implicated in the placebo response, such as the descending pain modulatory network. ${ }^{1}$ However, other possibilities exist. Greater fluctuations in pain levels in patients with DPN than PHN, in part related to metabolic factors, specifically changes in ambient blood glucose, may act as a conditioning stimulus for the placebo response. Amelioration of hypoglycemia or hyperglycemia may also underlie spontaneous improvement in the DPN group. Also, opioids were a permitted concomitant medication in the PHN but not DPN trials. Exogenous opioids could antagonize those mechanisms of the placebo response mediated by endogenous opioids.

Finally, patient characteristics and trial-related factors may be responsible. Substantially more of the DPN studies were conducted postapproval; patients on placebo in DPN studies had a younger mean age ( $\sim 59$ years) than those in PHN studies ( $\sim 70$ years), and DPN studies had a longer mean duration (11.5 and 9.1 weeks for high and low placebo-response studies, respectively) than PHN studies (7.0 weeks). Combined DPN/PHN studies, which in part control for these trial-related factors, yield equivocal results. In one (A0081081), patients with DPN had a higher placebo response than patients with PHN ( -2.32 versus -1.65$)$ over 9 weeks, whereas in the other (1008-155) there was little difference between DPN and PHN ( -1.78 versus -1.86$)$ over 12 weeks.

Remission may underlie a response in the placebo group, particularly in PHN, a disorder that remits spontaneously, particularly in the first 6 months of the disease. The present data, in which a shorter duration of PHN was associated with a greater placebo response, lend some support 
Table 5 Univariate predictors of change in pain at endpoint in the placebo population across all studies for categorical variables: being female, higher active treatment:placebo ratio, and studies conducted postapproval are significantly associated with a higher placebo response

\begin{tabular}{|c|c|c|c|c|c|c|}
\hline \multirow[t]{2}{*}{ Variable } & \multicolumn{3}{|c|}{ DPN } & \multicolumn{3}{|c|}{ PHN } \\
\hline & $\mathbf{n}$ & Mean (SD) ${ }^{a}$ & $P$-value & $\mathbf{n}$ & Mean (SD) ${ }^{\mathrm{a}}$ & $P$-value \\
\hline Sex & & & $<0.000$ I & & & 0.0016 \\
\hline Female & 466 & $-1.85(2.22)$ & & 231 & $-1.12(1.92)$ & \\
\hline Male & 572 & $-1.64(2.11)$ & & 245 & $-0.91(1.82)$ & \\
\hline Site recruitment ${ }^{\mathrm{b}}$ & & & $<0.000$ I & & & 0.0036 \\
\hline$\leq 5$ & 735 & $-1.65(2.10)$ & & 367 & $-1.02(1.87)$ & \\
\hline $6-8$ & 231 & $-1.99(2.41)$ & & 91 & $-1.07(1.90)$ & \\
\hline $9-11$ & 40 & $-1.63(1.84)$ & & 18 & $-0.65(1.69)$ & \\
\hline$\geq 12$ & 32 & $-1.99(1.91)$ & & - & - & \\
\hline Pregabalin approval status ${ }^{c}$ & & & $<0.0001$ & & & 0.0028 \\
\hline Preapproval & 467 & $-1.47(2.11)$ & & 361 & $-0.85(1.88)$ & \\
\hline Postapproval & 571 & $-1.95(2.18)$ & & 115 & $-1.52(1.75)$ & \\
\hline Enrollment period ${ }^{d}$ & & & $<0.000$ I & & & 0.0136 \\
\hline Ist quartile & 224 & $-1.56(2.15)$ & & 46 & $-0.94(1.94)$ & \\
\hline 2nd quartile & 218 & $-1.77(2.29)$ & & 129 & $-0.99(1.87)$ & \\
\hline $3 r d$ quartile & 263 & $-2.03(2.18)$ & & 136 & $-0.98(1.83)$ & \\
\hline 4th quartile & 333 & $-1.60(2.05)$ & & 165 & $-1.08(1.90)$ & \\
\hline Ratio of active:controle & & & $<0.0001$ & & & 0.0028 \\
\hline $\mathrm{I}: \mathrm{I}$ & 287 & $-1.26(1.96)$ & & 84 & $-1.10(2.03)$ & \\
\hline$\geq 2: 1$ & 751 & $-1.92(2.21)$ & & 392 & $-0.99(1.84)$ & \\
\hline Sites per study, n & & & $<0.000$ I & & & 0.0028 \\
\hline $10-26$ & 222 & $-1.55(2.04)$ & & 116 & $-1.22(1.96)$ & \\
\hline $27-42$ & 82 & $-1.18(1.80)$ & & 186 & $-1.30(1.79)$ & \\
\hline $43-49$ & 357 & $-1.88(2.29)$ & & 81 & $-0.48(1.65)$ & \\
\hline $50-76$ & 377 & $-1.82(2.16)$ & & 93 & $-0.63(1.95)$ & \\
\hline
\end{tabular}

Notes: $P$-value based on Student's t-test; ${ }^{a}$ mean change (SD) from baseline in pain score at endpoint in the pooled placebo arms; ${ }^{b}$ number of patients recruited at each site; 'pregabalin approval status at the commencement of the study; ${ }^{d}$ point of patient enrollment into the study relative to full study population; ${ }^{\text {eratio }}$ of the total number of patients receiving active treatment to patients receiving placebo.

Abbreviations: DPN, diabetic peripheral neuropathy; PHN, postherpetic neuralgia; SD, standard deviation.

to this notion. In these studies, patients with pain present for at least 3 months after healing of the herpes zoster skin rash were allowed to enter the trial. These data suggest that extending the duration of pain after the healing of the rash as an entry criterion may help attenuate the placebo response.
This analysis shows that, over time, there has been a trend towards an increased placebo response in pregabalin trials in DPN and PHN, whereas there has been no corresponding change in the response to pregabalin. Pooled analyses of trials in other patient populations have also noted an increase in placebo response over time..$^{5-7,26,33-35} \mathrm{~A}$ meta-analysis of

Table 6 Univariate predictors of change in pain at endpoint in the placebo population across all studies for continuous variables: younger age, shorter duration of PHN, higher baseline pain score, and longer study duration are significantly associated with a higher placebo response

\begin{tabular}{|c|c|c|c|c|c|c|c|c|}
\hline \multirow[t]{2}{*}{ Variable } & \multicolumn{4}{|l|}{ DPN } & \multicolumn{4}{|c|}{ PHN } \\
\hline & $\mathbf{n}$ & $R$-square & $\beta^{a}$ & $P$-value & $\mathbf{n}$ & $R$-square & $\beta^{a}$ & $P$-value \\
\hline Age & $\mathrm{I}, 038$ & 0.05462 & 0.0138 & 0.0262 & 476 & 0.06461 & 0.0283 & 0.0007 \\
\hline Duration of $\mathrm{NeP}$ & 627 & 0.03579 & -0.0006 & 0.9830 & - & - & - & - \\
\hline Duration of diabetes & 685 & 0.02435 & -0.0014 & 0.8697 & - & - & - & - \\
\hline Duration of DPN & 367 & 0.04232 & -0.0068 & 0.8153 & - & - & - & - \\
\hline Duration of PHN & - & - & - & - & 476 & 0.05975 & 0.0070 & 0.0028 \\
\hline Baseline pain score & $\mathrm{I}, 038$ & 0.09065 & -0.2895 & $<0.0001$ & 476 & 0.04249 & -0.0375 & 0.5039 \\
\hline Study duration & $\mathrm{I}, 038$ & 0.11660 & -0.1958 & $<0.0001$ & 476 & 0.06967 & -0.1226 & 0.0002 \\
\hline
\end{tabular}

Notes: Not all studies recorded duration of illness; $P$-values based on Student's $t$-test; $\beta$ represents the change from baseline to endpoint in daily pain rating scale score associated with a one-unit change in the continuous variable; A negative $\beta$ implies each unit in the continuous variable is associated with a greater improvement in pain score with placebo.

Abbreviations: DPN, diabetic peripheral neuropathy; NeP, diabetic neuropathic pain; PHN, postherpetic neuralgia. 

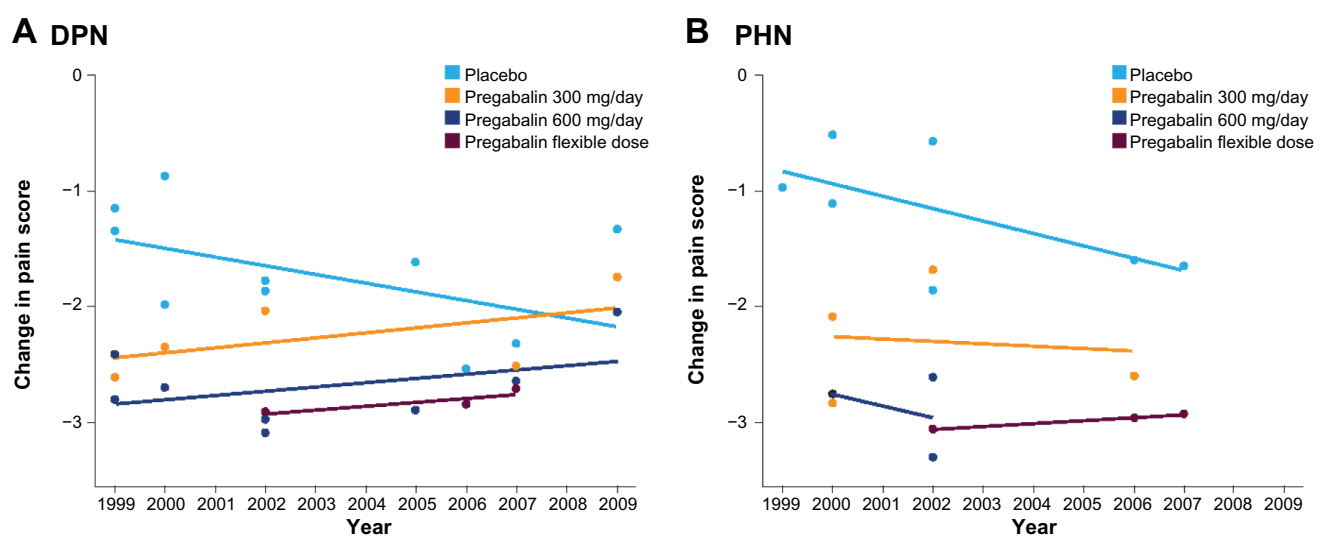

Figure 2 Mean change in placebo response at endpoint by study completion date.

Notes: Least squares mean change in pain score from baseline at endpoint for all treatment arms by the year the study was completed for (A) diabetic peripheral neuropathy (DPN) and (B) postherpetic neuralgia (PHN) trials.

75 trials in major depressive disorder noted a significant positive association between the proportion of patients responding to placebo and the year of publication (increase in the proportion of patients responding to placebo of approximately $7 \%$ per decade between 1981 and 2000). ${ }^{33}$ However, a more recent analysis of 96 trials between 1980 and 2005 confirmed the relationship between study year and placebo response with clinician rating but not with patient self-rating scales. ${ }^{36}$ It is not clear why there has been this increase in placebo response over time, but more recent trials tend to be of longer duration and, with clinical trials now being more common, more likely to include younger patients with shorter disease duration. These factors were associated with a greater placebo response in this analysis.

In the present analysis, a higher baseline pain score was associated with a higher placebo response. This has been observed in other analyses of studies in DPN, fibromyalgia, and depression in which, as with this analysis, both negative

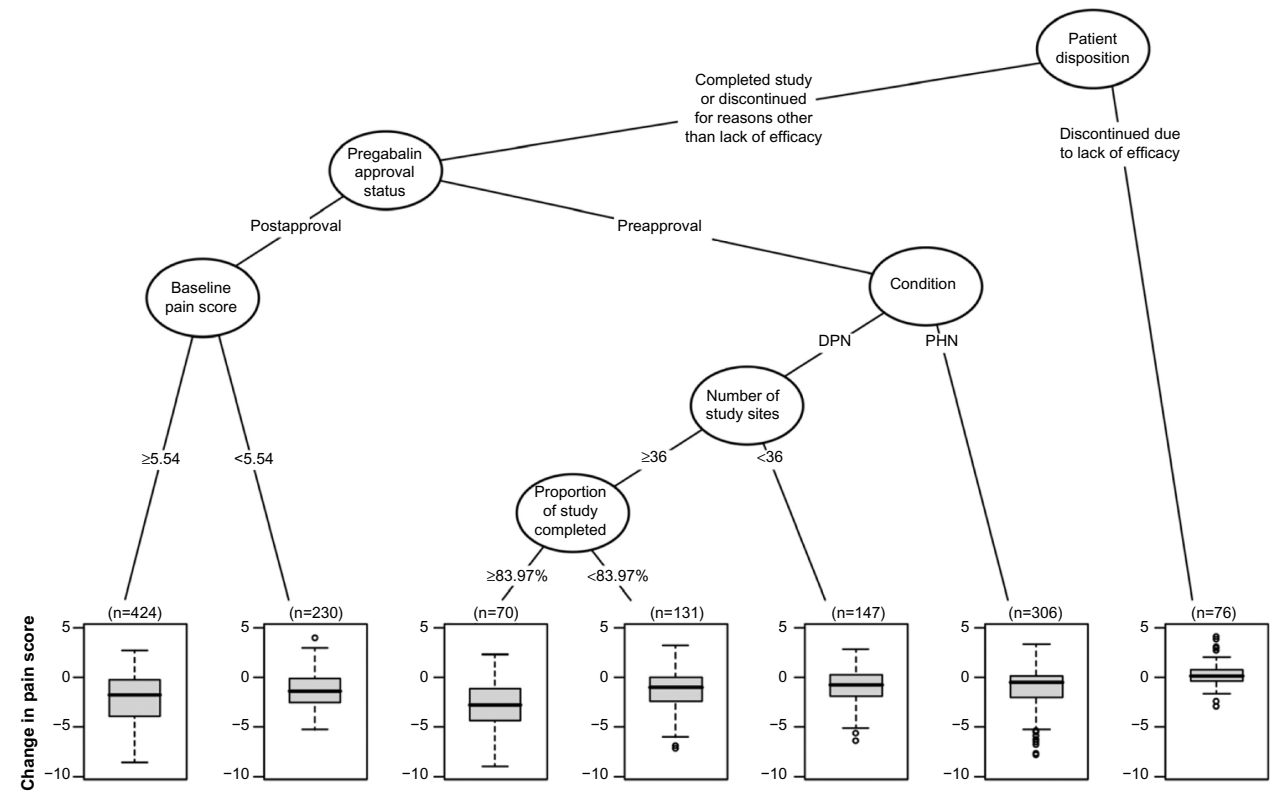

Figure 3 Regression-tree analysis of placebo response.

Notes: Box-and-whiskers plots showing median change in pain score with interquartile range; The first separation is on the status of the patients; Those who discontinued from the study due to lack of efficacy had the smallest placebo response; Of those who did not discontinue from the study due to lack of efficacy, patients who were from studies conducted preapproval of pregabalin had a lower placebo response; Of those from studies conducted postapproval of pregabalin, patients who had a baseline pain score $<5.54$ had a lower placebo response; Of those from studies conducted preapproval of pregabalin, those from postherpetic neuralgia (PHN) studies had a lower placebo response; Of those from diabetic peripheral neuropathy (DPN) studies, patients from studies with $<36$ sites had a lower placebo response; Of those from studies with $\geq 36$ sites, patients who remained in the study for $<83.97 \%$ of its duration had a lower placebo response; The highest placebo response was in patients who did not discontinue from the study due to lack of efficacy, were in studies conducted postapproval, were patients with DPN, were in studies with $\geq 36$ sites, and those who remained in the study for $\geq 83.97 \%$ of its duration. 
and positive studies were included. ${ }^{5,36}$ Some recent studies have excluded patients with the highest baseline pain scores (to increase the drug-placebo difference) ${ }^{37}$ However, inherent to this and other approaches to increase assay sensitivity by excluding placebo is the unresolved question of whether placebo and drug responses are independent, additive, or interactive, and whether excluding those most likely to respond to placebo also excludes those most likely to respond to active treatment.

There are limitations to this analysis. Only trials of pregabalin were included; therefore, the findings may not be applicable to other interventions. In addition, given the variability in design of the trials included, direct comparisons may not always be appropriate, particularly as only a limited number of the studies analyzed were high placebo-response studies.

A higher placebo response can limit the ability of a trial to discern a significant treatment effect, resulting in a falsenegative, failed trial. ${ }^{1}$ Determination of factors that influence patients' responses to placebo may assist in the design of trials that are able to more accurately and sensitively measure a treatment effect. By increasing assay sensitivity, efficacious treatments may be identified more quickly, reducing the number of trials and limiting the exposure of patients to placebo and unproven medications. ${ }^{7}$

\section{Acknowledgments}

This study was sponsored by Pfizer Inc. We thank Dr Ed Whalen, Pfizer Inc, for helpful discussions and assistance with statistical analysis. Editorial/medical writing support was provided by Joshua Fink, PhD, of Engage Scientific Solutions and funded by Pfizer Inc.

\section{Disclosure}

Dr Freeman has served on Pfizer's scientific advisory board. Drs Emir and Parsons are employees of Pfizer Inc. The authors report no other conflicts of interest in this work.

\section{References}

1. Dworkin RH, Turk DC, Peirce-Sandner S, et al. Placebo and treatment group responses in postherpetic neuralgia vs. painful diabetic peripheral neuropathy clinical trials in the REPORT database. Pain. 2010;150(1): 12-16.

2. Thienel U, Neto W, Schwabe SK, Vijapurkar U; Topiramate Diabetic Neuropathic Pain Study Group. Topiramate in painful diabetic polyneuropathy: findings from three double-blind placebo-controlled trials. Acta Neurol Scand. 2004;110(4):221-231.

3. Silver M, Blum D, Grainger J, Hammer AE, Quessy S. Double-blind, placebo-controlled trial of lamotrigine in combination with other medications for neuropathic pain. J Pain Symptom Manage. 2007;34(4): 446-454.
4. Vinik AI, Tuchman M, Safirstein B, et al. Lamotrigine for treatment of pain associated with diabetic neuropathy: results of two randomized, double-blind, placebo-controlled studies. Pain. 2007;128(1-2): 169-179.

5. Häuser W, Bartram-Wunn E, Bartram C, Reinecke H, Tölle T. Systematic review: Placebo response in drug trials of fibromyalgia syndrome and painful peripheral diabetic neuropathy-magnitude and patient-related predictors. Pain. 2011;152(8):1709-1717.

6. Irving $\mathrm{G}$. The placebo response: relationship to outcomes in trials of postherpetic neuralgia. Clin Drug Investig. 2010;30(11):739-748.

7. Katz J, Finnerup NB, Dworkin RH. Clinical trial outcome in neuropathic pain: relationship to study characteristics. Neurology. 2008;70(4): 263-272.

8. Dworkin RH, Turk DC, Peirce-Sandner S, et al. Considerations for improving assay sensitivity in chronic pain clinical trials: IMMPACT recommendations. Pain. 2012;153(6):1148-1158.

9. Katz N. Methodological issues in clinical trials of opioids for chronic pain. Neurology. 2005;65(12 Suppl 4):S32-S49.

10. Richter RW, Portenoy R, Sharma U, Lamoreaux L, Bockbrader H, Knapp LE. Relief of painful diabetic peripheral neuropathy with pregabalin: a randomized, placebo-controlled trial. J Pain. 2005;6(4): 253-260.

11. Lesser H, Sharma U, LaMoreaux L, Poole RM. Pregabalin relieves symptoms of painful diabetic neuropathy: a randomized controlled trial. Neurology. 2004;63(11):2104-2110.

12. Sharma U, Griesing T, Emir B, Young JP Jr. Time to onset of neuropathic pain reduction: a retrospective analysis of data from nine controlled trials of pregabalin for painful diabetic peripheral neuropathy and postherpetic neuralgia. Am J Ther. 2010;17(6):577-585.

13. Sabatowski R, Gálvez R, Cherry DA, et al; 1008-045 Study Group. Pregabalin reduces pain and improves sleep and mood disturbances in patients with post-herpetic neuralgia: results of a randomised, placebocontrolled clinical trial. Pain. 2004;109(1-2):26-35.

14. Freynhagen R, Strojek K, Griesing T, Whalen E, Balkenohl M. Efficacy of pregabalin in neuropathic pain evaluated in a 12-week, randomised, double-blind, multicentre, placebo-controlled trial of flexible- and fixed-dose regimens. Pain. 2005;115(3):254-263.

15. Dworkin RH, Corbin AE, Young JP Jr, et al. Pregabalin for the treatment of postherpetic neuralgia: a randomized, placebo-controlled trial. Neurology. 2003;60(8):1274-1283.

16. Rosenstock J, Tuchman M, LaMoreaux L, Sharma U. Pregabalin for the treatment of painful diabetic peripheral neuropathy: a double-blind, placebo-controlled trial. Pain . 2004;110(3):628-638.

17. Tölle T, Freynhagen R, Versavel M, Trostmann U, Young JP. Pregabalin for relief of neuropathic pain associated with diabetic neuropathy: a randomized, double-blind study. Eur J Pain. 2008;12(2):203-213.

18. van Seventer R, Feister HA, Young JP, Stoker M, Versavel M, Rigaudy L. Efficacy and tolerability of twice-daily pregabalin for treating pain and related sleep interference in postherpetic neuralgia: a 13-week, randomized trial. Curr Med Res Opin. 2006;22(2):375-384.

19. Stacey BR, Barrett JA, Whalen E, Phillips KF, Rowbotham MC. Pregabalin for postherpetic neuralgia: placebo-controlled trial of fixed and flexible dosing regimens on allodynia and time to onset of pain relief. J Pain. 2008;9(11):1006-1017.

20. Arezzo JC, Rosenstock J, Lamoreaux L, Pauer L. Efficacy and safety of pregabalin $600 \mathrm{mg} / \mathrm{d}$ for treating painful diabetic peripheral neuropathy: a double-blind placebo-controlled trial. BMC Neurol. 2008;8:33.

21. Guan Y, Ding X, Cheng Y, et al. Efficacy of pregabalin for peripheral neuropathic pain: results of an 8-week, flexible-dose, double-blind, placebo-controlled study conducted in China. Clin Ther. 2011;33(2): 159-166.

22. Satoh J, Yagihashi S, Baba M, et al. Efficacy and safety of pregabalin for treating neuropathic pain associated with diabetic peripheral neuropathy: a 14 week, randomized, double-blind, placebo-controlled trial. Diabet Med. 2011;28(1):109-116.

23. Melzack R. The short-form McGill Pain Questionnaire. Pain. 1987; 30(2):191-197. 
24. Dworkin RH, Turk DC, Wyrwich KW, et al. Interpreting the clinical importance of treatment outcomes in chronic pain clinical trials: IMMPACT recommendations. J Pain. 2008;9(2):105-121.

25. Khan A, Khan SR, Walens G, Kolts R, Giller EL. Frequency of positive studies among fixed and flexible dose antidepressant clinical trials: an analysis of the food and drug administration summary basis of approval reports. Neuropsychopharmacology. 2003;28(3):552-557.

26. Papakostas GI, Fava M. Does the probability of receiving placebo influence clinical trial outcome? A meta-regression of double-blind, randomized clinical trials in MDD. Eur Neuropsychopharmacol. 2009;19(1):34-40.

27. Macedo A, Farré M, Baños JE. A meta-analysis of the placebo response in acute migraine and how this response may be influenced by some of the characteristics of clinical trials. Eur J Clin Pharmacol. 2006;62(3): 161-172.

28. Patel SM, Stason WB, Legedza A, et al. The placebo effect in irritable bowel syndrome trials: a meta-analysis. Neurogastroenterol Motil. 2005;17(3):332-340.

29. Price DD, Finniss DG, Benedetti F. A comprehensive review of the placebo effect: recent advances and current thought. Annu Rev Psychol. 2008;59:565-590.

30. Enck P, Benedetti F, Schedlowski M. New insights into the placebo and nocebo responses. Neuron. 2008;59(2):195-206.
31. Cepeda MS, Berlin JA, Gao CY, Wiegand F, Wada DR. Placebo response changes depending on the neuropathic pain syndrome: results of a systematic review and meta-analysis. Pain Med. 2012;13(4): 575-595.

32. Quessy SN, Rowbotham MC. Placebo response in neuropathic pain trials. Pain. 2008;138(3):479-483.

33. Walsh BT, Seidman SN, Sysko R, Gould M. Placebo response in studies of major depression: variable, substantial, and growing. JAMA. 2002; 287(14):1840-1847.

34. Khan A, Bhat A, Kolts R, Thase ME, Brown W. Why has the antidepressant-placebo difference in antidepressant clinical trials diminished over the past three decades? CNS Neurosci Ther. 2010;16(4): 217-226.

35. Rheims S, Perucca E, Cucherat M, Ryvlin P. Factors determining response to antiepileptic drugs in randomized controlled trials. A systematic review and meta-analysis. Epilepsia. 2011;52(2):219-233.

36. Rief W, Nestoriuc Y, Weiss S, Welzel E, Barsky AJ, Hofmann SG. Meta-analysis of the placebo response in antidepressant trials. J Affect Disord. 2009;118(1-3):1-8.

37. Hewitt DJ, Ho TW, Galer B, et al. Impact of responder definition on the enriched enrollment randomized withdrawal trial design for establishing proof of concept in neuropathic pain. Pain. 2011;152(3): $514-521$
Journal of Pain Research

\section{Publish your work in this journal}

The Journal of Pain Research is an international, peer-reviewed, open access, online journal that welcomes laboratory and clinical findings in the fields of pain research and the prevention and management of pain. Original research, reviews, symposium reports, hypothesis formation and commentaries are all considered for publication.

\section{Dovepress}

The manuscript management system is completely online and includes a very quick and fair peer-review system, which is all easy to use. Visit http://www.dovepress.com/testimonials.php to read real quotes from published authors. 